\title{
CORROSION BEHAVIOUR OF STEEL/55\%AL-ZN ALLOY/PAINT SYSTEMS EXPOSED TO NATURAL AND ARTIFICIAL ENVIRONMENTS
}

\author{
Cecilia I. Elsner, ${ }^{1,2}$ Delia B. del Amo, ${ }^{1}$ Luis S. Hernández, ${ }^{3}$ and Alejandro R. Di Sarli ${ }^{1 *}$ \\ 1. CIDEPINT: Centro de Investigación y Desarrollo en Tecnología de Pinturas (CICPBA-CONICET-La Plata), Av. 52 s/n entre 121 y 122 \\ B1900AYB, La Plata, Argentina
}

2. Facultad de Ingeniería, Universidad Nacional de La Plata, Av. 1 Esq. 47. CP. B1900TAG, La Plata, Argentina

3. Instituto de Metalurgia, Universidad Autónoma de San Luis Potosí - UASLP, Av. Sierra Leona N550. Lomas $2^{\circ}$ Sección, 78210 , San Luis Potosí, SLP, Mexico

\begin{abstract}
The corrosion performance of steel/55\%Al-Zn alloy sheets pre-treated with $5 \% \mathrm{Fe}\left(\mathrm{NO}_{3}\right)_{3}+15 \% \mathrm{H}_{3} \mathrm{PO}_{4}$ solution, and then coated with acrylic (AC), alkyd (AQ), vinyl (VL), solvent-based epoxy (ES) or waterborne epoxy (EA) corrosion-inhibiting primers + a barrier topcoat alkyd paint was studied. Exposure conditions included weathering chambers and natural atmospheres (La Plata-Argentina and San Luis-Potosí, México). The panels' behaviour was evaluated through visual inspections and EIS measurements. Their results allowed inferring that: (1) most of the painting systems have a satisfactory performance during their exposure to the accelerated weathering chamber or the natural atmospheric stations and (2) the correlation between them allowed explaining some problems arising in service. This information will allow extending the useful life by adjusting the painting system formulation.
\end{abstract}

Keywords: steel/55\%Al-Zn, painting systems, adhesion, weathering, corrosion, blistering, EIS

\section{INTRODUCTION}

$\mathrm{W}$ hen exposed to aggressive media, metal or alloy stability depends upon the protective properties of the surface film formed. Chemical composition, conductivity, adherence, solubility, hygroscopicity and morphological characteristics determine the film capacity to work as a controlling barrier. ${ }^{[1]}$ In this regard, the steel galvanic protection by means of zinc or zinc alloys is a common example; not only due to the fact that zinc is electrochemically more active than steel, but also because it produces a barrier effect by means of the corrosion products precipitated on the metallic surface thus corroding preferentially. In particular, zinc-based coatings are widely used to protect steel structures against atmospheric corrosion, ${ }^{[2]}$ due to the protective properties afforded by an insoluble film of basic carbonate. However, if the exposure conditions are such that there are changes of the ambient variables like atmospheric conditions, UV radiation intensity, type and level of pollutants, wet-dry cycles, depletion of air by high humidity or a medium containing strongly aggressive species like chloride or sulphate ions, the zinc could dissolve forming soluble, less dense and scarcely protective corrosion products which sometimes lead to localised corrosion. $^{[2,3]}$ This condition can be reached during the storage and transportation of galvanized steel sheets or when they are exposed to marine and/or industrial environments. ${ }^{[4]}$

For years, although the protective effect of zinc and aluminum combinations was known, they were not used until the discovery that silicon inhibits the fast alloying reaction with steel. ${ }^{[5]}$ Thus, the alloy consisting of $55 \% \mathrm{Al}, 1.6 \% \mathrm{Si}$, the rest zinc, known as Zincalume ${ }^{\circledR}$, was selected from a systematic study, providing an excellent combination of galvanic protection and low corrosion rate. The microstructure of the alloy coated steel, which forms on cooling, is essentially two phases comprising about $80 \%$ by volume of a dendritic aluminum rich phase and the remainder interdendritic zinc rich phase with a thin intermetallic layer next to the steel substrate. When the coating corrodes, initially the zinc corrodes preferentially until the formation of corrosion products reduces further activity in these areas. During the initial corrosion stage, the coating behaves like zinc coating. In the later corrosion stages, when the coating consists essentially of zinc corrosion products carried in an aluminum rich matrix, the corrosion becomes more characteristic of the aluminum rich phase thus resulting in a lower corrosion rate. ${ }^{[6]}$

However, when a higher protection degree of these metallic surfaces is taken into consideration, properly chosen painting systems can provide a more effective corrosion-inhibiting barrier and also a better aesthetic appearance ${ }^{[7]}$ Some exposure conditions are so aggressive that both protective systems (metallic + organic coatings) must be applied to get longer effectiveness. Such a combination, referred to as duplex system, has demonstrated a synergistic effect when compared to one component coating systems. This better corrosion protection is attributed to the double action afforded by the $55 \% \mathrm{Al}-\mathrm{Zn}$ layer (cathodic protection + blockage of its defects by the corrosion products), and also by the pigmented paint system (barrier effect + steel corrosion-inhibition) ${ }^{[8]}$ Besides, this duplex system requires less reconditioning and repairing of coating systems after transportation and assembly on site.

The mechanism responsible for the protective action of paint coatings is highly complex because it depends upon the

\footnotetext{
*Author to whom correspondence may be addressed.

E-mail address: ardisarli@cidepint.gov.ar, ardisarli@gmail.com Can. J. Chem. Eng. 92:623-632, 2014

(C) 2013 Canadian Society for Chemical Engineering DOI 10.1002/cjce.21874

Published online 23 August 2013 in Wiley Online Library (wileyonlinelibrary.com).
} 
simultaneous action of different factors. Without considering their intended function (functional, decorative or protective), the paint must adhere satisfactorily to the underlying substrate. ${ }^{[9]}$

The permeability of the organic film is vital in metallic substrate corrosion, since this property is directly connected to the transport of environmental corrosion-inducing chemicals through the polymeric matrix. In this sense, it should be remarked that mainly water and oxygen could permeate through the paint film, at least to some extent, even if none of the intrinsic structural defects are present. For these reasons, the painted metal resistance to degradation produced by weathering is a very important variable, since it defines the material durability. Within this concept, the corrosion and resistance to weathering (UV degradation, oxygen, humidity, etc.) are separately evaluated. The corrosion resistance depends upon the permeability (barrier effect) of the painting system and galvanic layer as well as to the inhibitive capacity of the contained anticorrosive pigments. The weathering degradation (loss of gloss and/or adhesion, chalking, cracking, blistering, etc.) takes place at shorter times and depends mainly on the topcoat paint properties. All these concepts were subjected to intensive studies and satisfactory protective duplex systems using solvent-base paints were developed. ${ }^{[8,10]}$ However, rigid environmental legislation to protect the public health and the environment requires more ecofriendly systems. Therefore, their replacement by other systems with equal or even greater protective properties involves new and accelerated studies.

From this point of view, CIDEPINT has an ongoing research program, which deals with the elucidation of physicochemical phenomena occurring within and under paint coatings, considering defects in films, porous films, metal/coating adhesion, surface treatment and/or pre-treatment, corrosion, blistered coatings and cathodic protection. As part of this program, an evaluation of the protective performance of five pre-treated steel/55\% Al-Zn/ painting system arrangements exposed to natural or accelerated weathering tests is reported here. Although the extrapolation of accelerated test results do not fit linearly to the actual performance of the coatings in their service life, it can supply useful information related to the rate and form of the corrosion-inhibiting system degradation. In most cases, such information can help to improve the paint formulation and/or the painting scheme design. Therefore, with this purpose, replicates of each coated steel system were subjected either to accelerated weathering for $300 \mathrm{~h}$, performed in accordance with the ASTM G-153-00a standard, or to natural weathering at La Plata (Argentina) and San Luis-Potosí (Mexico) stations for 2 years. Before and at the end of the exposures the paint adhesion was evaluated using the tape test
(ASTM D-3359/08), while, at the end of the tests, the samples blistering and white corrosion degrees were respectively classified according to the ASTM D-714-87/00 and D-610/08 standards, and their cracking, checking and/or flaking degrees according to the ASTM D-661/05, D-660/05 and D-772/05 standards, respectively.

Together with the visual inspections, electrochemical impedance measurements to determine changes in the electrical and electrochemical properties of each steel $/ 55 \% \mathrm{Al}-\mathrm{Zn} /$ paint system, as a function of the exposure time, were also performed.

The large amount of data collected from standardised as well as electrochemical tests were interpreted on the basis of their correlation with some physicochemical processes that may occur in pre-treated steel $/ 55 \% \mathrm{Al}-\mathrm{Zn} /$ paint film/exposure medium systems.

\section{EXPERIMENTAL DETAILS}

\section{Samples}

Carbon steel sheets $(15 \mathrm{~cm} \times 8 \mathrm{~cm} \times 0.2 \mathrm{~cm})$, whose percentage chemical composition, balanced of iron, was: C (0.16), Mn (0.54), Si $(0.05)$, S (0.01), P (0.01) hot-dip coated with a layer of $55 \% \mathrm{Al}-$ $\mathrm{Zn}$ alloy (Zn 43.33\%; Al 55\%; Si 1.6\%; Pb 0.03\%; Fe 0.04\% and $22.5 \mu \mathrm{m}$ thickness) were used as metallic substrate. They were degreased by immersion in $5 \% \mathrm{Na}_{2} \mathrm{CO}_{3}$ solution, rinsed with distilled water to eliminate any surface contamination, and then pre-treated under controlled laboratory conditions with $5 \% \mathrm{Fe}$ $\left(\mathrm{NO}_{3}\right)_{3}+15 \% \mathrm{H}_{3} \mathrm{PO}_{4}$ solution.

The anticorrosive paints (Table 1) were formulated and prepared in the laboratory. According to the literature, $30 \%(\mathrm{v} / \mathrm{v})$ of the primers' total pigment content was composed of zinc molybdophosphate anticorrosive pigment, while the rest was Bentonite (14\%), $\mathrm{TiO}_{2}(3.5 \%), \mathrm{BaSO}_{4}(3.7 \%)$, Talc (3.4\%) and Mica $(7.0 \%) .{ }^{[11]}$ This last pigment was incorporated to improve the paint barrier effect as well as to reduce the flush rusting degree caused by the waterborne paints. ${ }^{[12]}$ In the water or solvent-base paints the PVC was $20 \%$ and $40 \%$, respectively. The topcoat paint was a commercial-grade type alkyd.

As the primer paint elaboration was made at laboratory scale, brushing was the preferred application method maintaining the same conditions for all the samples. After the application of the painting systems, the painted plates were placed in a dessicator cabinet until completely dry. Next, measurements of dry film thickness (Table 2) were taken with an Elcometer 300 coating thickness gauge, using a bare plate and standards of known thickness as references.

Table 1. Main characteristics of the formulated primers

\begin{tabular}{|c|c|c|c|c|c|c|}
\hline \multirow[b]{2}{*}{ Primer } & \multirow[b]{2}{*}{ Resin } & \multirow[b]{2}{*}{ Solvent } & \multirow[b]{2}{*}{ Plasticizer } & \multicolumn{3}{|c|}{ Pigments } \\
\hline & & & & Anticorrosive & Filler & Hiding \\
\hline Acrylic & Acrylic-styrene & Water & - & Zinc molibdo phosphate & Bentonite & $\mathrm{TiO}_{2}$ (rutile) \\
\hline Alkyd & Alkyd & White spirit/toluene $1: 1(\mathrm{v} / \mathrm{v})$ & - & Zinc molibdo phosphate & Talk mica baryte & $\mathrm{TiO}_{2}$ (rutile) \\
\hline Epoxy $_{\text {solv }}$ & Epoxy-polyamide & $\begin{array}{l}\text { Xylene/MIK/butoxyethanol } \\
\text { 13:45:42 (v/v) }\end{array}$ & - & Zinc molibdo phosphate & Talk mica baryte & $\mathrm{TiO}_{2}$ (rutile) \\
\hline Epoxy $_{a q}$ & a & Water + coalescent & - & Zinc molibdo phosphate & Talk mica baryte & $\mathrm{TiO}_{2}$ (rutile) \\
\hline Vinyl & b & MIK/toluene 1:1 (v/v) & $\begin{array}{l}\text { Tricresyl } \\
\text { phosphate }\end{array}$ & Zinc molibdo phosphate & Talk mica baryte & $\mathrm{TiO}_{2}$ (rutile) \\
\hline
\end{tabular}

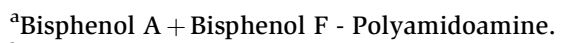

bolyvinyl Chloride-Acetate copolymer. 


\begin{tabular}{|lllc|}
\hline \multicolumn{3}{l}{ Table 2. Identification and total thickness of the painting system } \\
\hline $\begin{array}{l}\text { Painting } \\
\text { system }\end{array}$ & $\begin{array}{c}\text { Anticorrosive } \\
\text { primer }\end{array}$ & $\begin{array}{c}\text { Topcoat } \\
\text { paint }\end{array}$ & $\begin{array}{c}\text { Total } \\
\text { thickness }(\mu \mathrm{m})\end{array}$ \\
\hline AC & Acrylic $_{\text {Alkyd }}$ & Alkyd & $125 \pm 10$ \\
ES & Alkyd $_{\text {Epolv }}$ & Alkyd & $120 \pm 10$ \\
EA & Epoxy $_{\text {aq }}$ & Alkyd & $119 \pm 10$ \\
VL & Vinyl & Alkyd & $130 \pm 10$ \\
\hline
\end{tabular}

\section{Standardised Tests}

Ten replicates of each type of the coated steel samples described above were subjected to accelerated weathering for $300 \mathrm{~h}$ (empirically equivalent to around 2 years exposure to La Plata atmosphere), performed in accordance with the ASTM G-153-00a standard. On the other hand, 150 replicates (30 of each coated sample) were exposed to natural weathering at La Plata (Argentina) and San Luis-Potosí (Mexico) stations for 2 years; the average values of the climatic variables corresponding to both stations are summarised in Table 3 . At the end of these tests, the size and frequency of blisters, as well as the rusting (white corrosion) degree, were evaluated according to ASTM D-714-87/00 and D-610/08 standards, respectively, while the cracking, checking and/or flaking degrees were evaluated according to ASTM D-661/93 (Reapproved 2005), D-660/93 (Reapproved 2005) and D-772/86 (Reapproved 2005) standards, respectively.

\section{Electrochemical Measurements}

For the electrochemical impedance (EIS) measurements carried out previous to initiating the exposure tests, and then periodically together with the visual inspections, a cylindrical clamp-on acrylic (polymethyl methacrylate) cell was positioned on the painted panel by an O-ring defining a surface area of $15.9 \mathrm{~cm}^{2}$. A special tip supported the three electrodes; the electrochemical cell contained a Pt-Rh mesh counter-electrode with negligible impedance, oriented parallel to the working electrode (painted metal surface). A glasslinear Saturated Calomel tipped Reference Electrode (SCE), referred to in the text, was positioned, together with the counterelectrode, close to the exposed painted steel surface panel. All the EIS measurements were performed, after $1 \mathrm{~h}$ of wetting with the electrolyte formed by dissolving the salts deposited on the sample surface in $100 \mathrm{~mL}$ of distilled water, using a Solartron 1255 FRA $^{\circledR}$ coupled to an Impedance Potentiostat-Galvanostat Omnimetra PG-19A ${ }^{\circledR}$, and both controlled by the Zplot ${ }^{\circledR}$ software. Impedance spectra collected between $10^{5} \mathrm{~Hz}$ and $10 \mathrm{mHz}$ were analysed and interpreted on the basis of equivalent electrical circuit models, optimising the values of the circuit parameters by using the Boukamp' program. ${ }^{[13]}$

All the electrochemical experiments were carried out at laboratory temperature $\left(23 \pm 2^{\circ} \mathrm{C}\right)$ and with the electrochemical cell in a Faraday cage to reduce external interferences as much as possible.
Taking into account that the corrosion behaviour of passivated, painted and/or multi coated materials strictly depends on the production procedure, the electrochemical tests were carried out on three replicates of each sample type and the average results obtained for them are the reported in the following figures.

\section{EXPERIMENTAL RESULTS AND DISCUSSION}

\section{Atmospheric Exposure Test}

It is known that all the materials degrade under the influence of atmospheric factors such as oxygen, humidity and/or pollutants $\left(\mathrm{SO}_{2}, \mathrm{NaCl}, \mathrm{NO}_{x}\right.$, etc. $)$. Another important degradation source is sun radiation, particularly its UV rays. All these influences compose the so-called 'Macroclimate' of a determined zone. ${ }^{[14]}$ In other words, 'Microclimate' is defined as the specific climate formed around an object and is of vital importance to understand the atmospheric mechanisms causing the materials degradation. Among the parameters used to define it are the surface time of wetness (TOW), the heating by sun radiation (mainly infrared), and the acidic nature ions $\left(\mathrm{SO}_{3}{ }^{2-}, \mathrm{NO}_{2}{ }^{-}, \mathrm{Cl}^{-}\right)$gathering within the aqueous layer deposited on the object. On the other hand, the atmospheric corrosion process is the sum of partial corrosion processes taking place each time an electrolyte layer deposits on the surface metal. Rain, snow, fog and/or humidity condensation produced by temperature changes are the main promoters of atmospheric corrosion. The value of some climatological variables characterising the average exposure conditions corresponding to the stations used in the present work are shown in Table 3. The greater aggressiveness of La Plata station with regard to the San Luis one was attributed to its higher relative humidity, more severe and lengthy TOW as well as surface runoff supported by the replicates tested in that station. However the protective behaviour of the tested painting systems was not found to be significantly different.

\section{Adhesion}

The amount of adhesion loss depends upon both the exposure aggressiveness intensity and the strength of the metal/paint bonding. Several authors claimed the damage effect (interfacial bond breaks) of the so-called wet-adhesion. ${ }^{[15]}$ In the rather qualitative tape-test the scales used by the ASTM D-3359/09 standard to classify the specimens is from $0 \mathrm{~B}$ to $5 \mathrm{~B}$, where $0 \mathrm{~B}$ corresponds to a very poor (percent of area removed $>65 \%$ ) and $5 \mathrm{~B}$ to a very good adhesion (percent of area removed $0 \%$ ), respectively.

Before beginning the tests, replicated panels were subjected to the tape-test at several areas of their body. At the end of the test exposures, the same panels were visually inspected and their general state classified again. Thus, the obtained results for the five painting systems described in Table 2 are summarised in Table 4 . It shows that the classification of the adhesion properties performed before any other test, with values between $5 \mathrm{~B}$ and $4 \mathrm{~B}$, was highly satisfactory, while the scattering among the measurements for each panel was absent. As well, the same Table shows that after the

\begin{tabular}{|c|c|c|c|c|c|c|}
\hline Station & $\mathrm{T}\left({ }^{\circ} \mathrm{C}\right)$ & RH (\%) & TOW f. annual & Rain $\left(m m y^{-1}\right)$ & {$\left[\mathrm{SO}_{2}\right]\left(\mathrm{mg} \mathrm{m}^{-2} \mathrm{~d}^{-1}\right)$} & {$\left[\mathrm{Cl}^{-}\right]\left(\mathrm{mg} \mathrm{m}^{-2} \mathrm{~d}^{-1}\right)$} \\
\hline La Plata & 17.00 & 78.00 & 0.59 & $1,300.00$ & 7.20 & Insignificant \\
\hline San Luis-Potosí & 18.00 & 60.00 & 0.16 & 370.00 & 21.00 & Insignificant \\
\hline
\end{tabular}


Table 4. Paints adhesion results using the tape-test method (ASTM D-3359/97) before and after the exposure to the accelerated or natural atmospheres

\begin{tabular}{lllllc}
\hline & \multicolumn{2}{c}{ Before the tests } & & \multicolumn{2}{c}{ After the tests } \\
\cline { 2 - 3 } \cline { 5 - 6 } Sample & Centre & Edges & & Centre & Edges \\
\hline AC & $5 B$ & $5 B$ & & $5 B$ & $5 B$ \\
AQ & $4 B$ & $4 B$ & & $4 B$ & $4 B$ \\
ES & $4 B$ & $4 B$ & & $4 B$ & $4 B$ \\
EA & $4 B$ & $4 B$ & & $4 B$ & $4 B$ \\
VL & $5 B$ & $5 B$ & & $5 B$ & $5 B$ \\
\hline
\end{tabular}

natural or accelerated weathering test no sample evidenced measurable changes in its adhesion forces or, in other words, during the tests no break of chemical bonds between the polymer layer and the alloy surface took place. In principle, such a result allowed to presume that the paint films behaved like an impervious layer and, in this manner, they prevented changes in the corresponding glass transition temperature $\left(T_{\mathrm{g}}\right)$. This is an extremely important effect in anticorrosive coatings since, as the $T_{\mathrm{g}}$ value decreases, the water, oxygen and ionic permeation increases favouring paint delamination by the breaking of paint/ alloy interface bonds.

\section{Blistering, white rusting, cracking, checking and/or flaking degrees}

The mechanism of formation and growth related to the paint film blistering, which involves a number of frequencies and sizes, may be explained assuming that water molecules permeation through organic coating develops at small-localised regions where local failure of the paint film adhesion takes place. As the exposure to the aqueous or wet environment continues, these areas grow and coalesce into larger units resulting in part or the total exposed area to become delaminated. The periodic visual inspection and standardised characterisation of the painted surface allowed the monitoring of the starting and evolution of the blistering, corrosion and/or other processes leading to reduce aesthetic and mechanical properties of each sample.

Table 5 displays blistering, white corrosion, cracking, checking and/or flaking data obtained for replicates of the steel/55\% Al-Zn/ paint systems subjected to natural or accelerated exposure under the conditions described in Table 3 or the ASTM G-153-00a standard, respectively. These data are a further representation of the protective and aesthetic properties provided by the topcoat paint. In this sense, the results obtained from visual inspections carried out after 2 years of exposure at the La Plata and Potosí stations (Figure 1 and Table 5) confirmed that:

(1) The samples protective performance was mostly highly satisfactory with ratings of 10 for blistering and white rusting, and no or small signals of topcoat paint deterioration. Exceptions to this statement were the AC, ES and VL systems exposed to the more aggressive climatic conditions of La Plata station since, once removed the paint films, on the bare metallic surfaces could be observed a small amount of the characteristics white corrosion products of the zinc. The rusting grade (9-8) and percentage of rusted area $(\leq 0.03 \%)$ in these samples was small enough to consider that at least from this point of view the corrosion protection given by the overall painting system could be improved by, for example, thickening the paint films to increase the barrier effect;

(2) the fact that the painting systems did not show blistering agrees entirely with the measured high adhesion values (see Table 4); and

(3) after 2 years of exposure, a severe checking (No. 4 or 2) was found in the painting system identified as AC and AQ samples exposed at La Plata station, while an also significant flaking ( 2 or 6 ) in the EA (at La Plata and Potosí) and VL samples (at La Plata station). These results were interpreted as a consequence of the fact that, added to the natural aging process, and mainly in the more aggressive atmosphere of La Plata station, the alkyd paint film was not able to follow

Table 5. State of the samples after 2 years exposure to the natural atmospheres of La Plata and San Luis stations

\begin{tabular}{|c|c|c|c|c|c|c|}
\hline \multirow[b]{2}{*}{ System } & \multirow[b]{2}{*}{ Station } & Blistering & White rusting & Cracking & Checking & Flaking \\
\hline & & Blister size/frequency & $\begin{array}{l}\text { White rusting grade/percent } \\
\text { of rusted surface }\end{array}$ & No. & No. (type) & No. \\
\hline \multirow[t]{2}{*}{$A C$} & La Plata & 10 & 9-P/0.03 & 10 & 4 (Irregular) & 10 \\
\hline & San Luis - Potosí & 10 & 10 & 8 & 10 & 10 \\
\hline \multirow[t]{2}{*}{ AQ } & La Plata & 10 & 10 & 10 & 2 (Irregular) & 10 \\
\hline & San Luis - Potosí & 10 & 10 & 10 & 10 & 10 \\
\hline \multirow[t]{2}{*}{ ES } & La Plata & 10 & 8-P/0.03 & 10 & 10 & 10 \\
\hline & San Luis - Potosí & 10 & 10 & 10 & 10 & 10 \\
\hline \multirow[t]{2}{*}{ EA } & La Plata & 10 & 10 & 10 & 10 & 2 \\
\hline & San Luis - Potosí & 10 & 10 & 10 & 10 & 6 \\
\hline \multirow[t]{2}{*}{ VL } & La Plata & 10 & $9-P / 0.03$ & 10 & 10 & 8 \\
\hline & San Luis - Potosí & 10 & 10 & 10 & 10 & 10 \\
\hline \multicolumn{7}{|c|}{ State of the samples after $300 \mathrm{~h}$ exposure to the accelerated weathering } \\
\hline $\mathrm{AC}$ & - & 10 & 10 & 10 & 10 & 10 \\
\hline AQ & - & 10 & 10 & 10 & 10 & 10 \\
\hline ES & - & 10 & 10 & 10 & 10 & 10 \\
\hline EA & - & 10 & 10 & 10 & 10 & 10 \\
\hline $\mathrm{VL}$ & - & 10 & 10 & 10 & 10 & 10 \\
\hline
\end{tabular}

White rusting distribution: S, Spot; G, General; P, Pinpoint. 

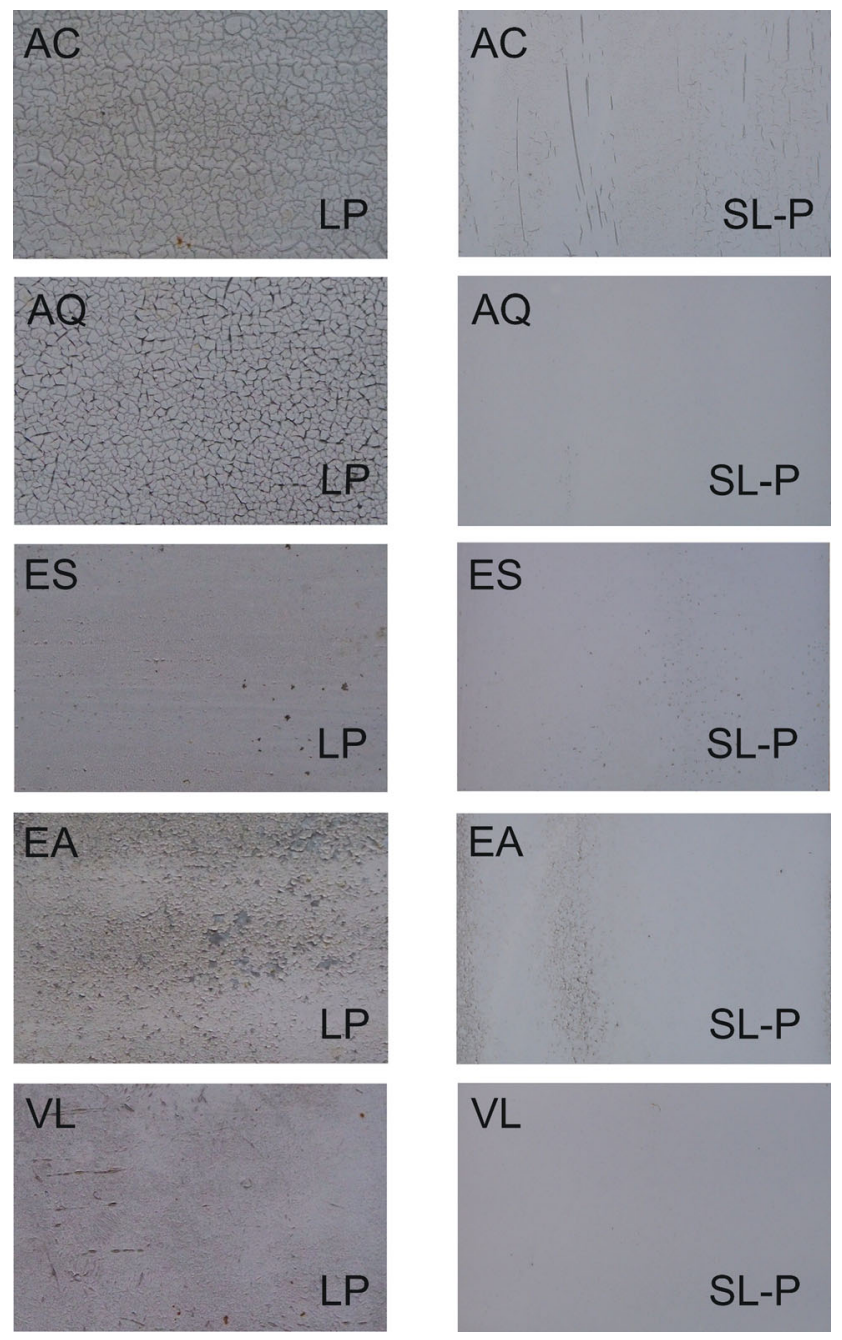

Figure 1. State of the samples after 2 years of exposure to the natural atmospheres of La Plata and Potosí stations.

the panels expansions and contractions due to some incompatibility with the respective primer film.

Table 5 also illustrates the excellent protective performance shown by all the samples after $300 \mathrm{~h}$ of exposure to the accelerated weathering test. The lack of degradation revealed by the alkyd topcoat paint was attributed to the fact that the strong interaction between the reactive components of the polymer and the chemically stable pigment titanium dioxide ${ }^{[16]}$ was enough to resist the exposure conditions imposed by the accelerated weathering test. In addition to the topcoat paint properties, the maintenance of the, in general, satisfactory protective and aesthetic performance by all the tested samples was ascribed to the contribution of the good adhesion and effective anticorrosive protection properties offered by the primers pigmented with zinc molybdophosphate.

\section{Electrochemical Tests}

\section{Corrosion potential}

Rest or corrosion potential $\left(E_{\text {corr }}\right)$ measurements and their time dependence for painted metals have been questioned with regard to their use as a technique for evaluating the anticorrosive

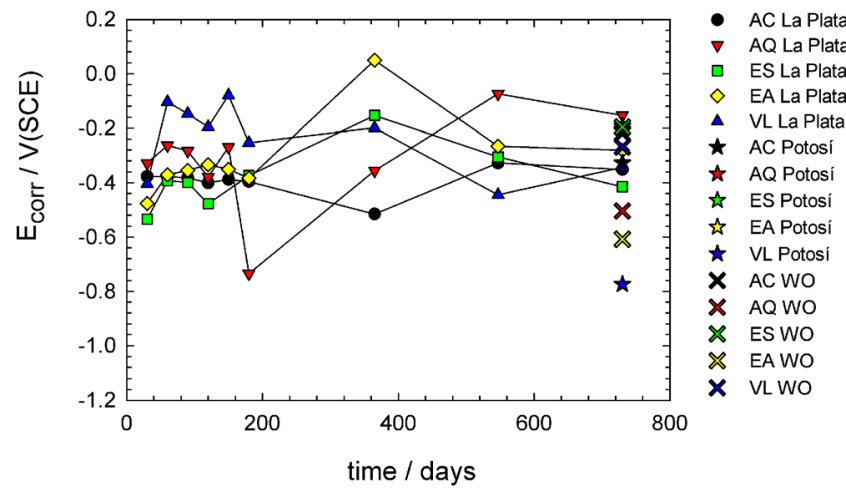

Figure 2. Plots showing the time dependence of the corrosion potential $\left(E_{\text {corr }}\right)$ during the exposure of the $A C, A Q, E A, E S$ and $V L$ samples to natural atmospheres of the La Plata and Potosí stations for 2 years, and to the accelerated weathering test for $300 \mathrm{~h}$.

resistance of organic coatings. ${ }^{[17]}$ However, these measured changes as a function of the exposure time to aqueous media have been successfully used as a simple tool to study the corrosion protection afforded by organic coatings. ${ }^{[18]}$ Depending upon the microstructure of the paint coating, especially its polymerisation degree, a certain period elapses until electrolyte penetration channels are established through which the underlying metal comes into contact with the medium. So, it is not surprising that, when a compact structure and high crosslinking level are accompanied by high film thickness, a few days of testing is not enough time for the electrolyte to enter in contact with the base metal of coated specimens, form the electrochemical double layer, and enable the measurement of a corrosion potential.

Figure 2 shows the corrosion potential $\left(E_{\text {corr }}\right)$ values measured for each coated steel sheet exposed to natural or artificial atmospheres. As can be seen, the aforementioned induction period necessary to measure the first more or less stabilised $E_{\text {corr }}$ values in painted samples was about 40 days of exposure, and also that these values ranged between -0.32 and $-0.52 \mathrm{~V} / \mathrm{SCE}$. Thereafter, and up to the end of the test, the measured values (only at La Plata station) remained much nobler than the corresponding to the bare low carbon steel $/ 55 \% \mathrm{Al}-\mathrm{Zn}$ alloy (between -0.9 and $-1.1 \mathrm{~V} / \mathrm{SCE}$ ) measured at the same station. ${ }^{[19]}$

Therefore, those potential values indicated that at least from the thermodynamic point of view the $55 \% \mathrm{Al}-\mathrm{Zn}$ alloy corrosion was strongly restricted.

Taking into account that the main difference among the steel/ $55 \% \mathrm{Al}-\mathrm{Zn} /$ painting systems was the primer formulation used in each case, it was assumed that the magnitude of the $E_{\text {corr }}$ displacements was predominantly associated with both the relative ease with which the water molecules could overcome the barrier effect provided by each painting system and the corrosion inhibiting properties afforded by the corresponding primer film. Therefore, taking into account these two factors and the good interfacial adhesion it was inferred that the protective properties were effective enough to delay the development of electrochemical activity at the paint $/ 55 \% \mathrm{Al}-\mathrm{Zn}$ interface and, therefore, changes in the cathodic/anodic areas relationship ${ }^{[20]}$ for 40 days. From now on, the protection may be attributed to the sum of effects acting simultaneously such as the paint system barrier protection and the pore blockage with the corrosion products mostly produced from the zinc dissolution reactions due to self-corrosion and/or when it galvanically protects the underlying steel. When this kind of protection is lost, or at least significantly diminished, other protective forms, for example those exerted by the anticorrosive 
zinc molybdophosphate pigment, certainly continue being active. Some authors ${ }^{[21]}$ suggested that both the phosphate and molybdenum compounds contribute to the anticorrosive protective mechanism through an effective steel repassivation at the underpaint crevices and pits.

\section{Impedance}

As far as the paint film is concerned, its barrier properties are of great interest because they control the transport of corrosive chemicals as well as the dissolution of the active pigments and their supply to the metal substrate. Reliable data on impedance evolution of coated metals provides valuable information to select and design the most adequate protective paint system for each practical situation.

Bode plots. The impedance modulus $(|Z|)$ and angle phase $(\theta)$ of $\mathrm{AC}, \mathrm{AQ}, \mathrm{ES}, \mathrm{EA}$ and VL samples as a function of their exposure time to the natural atmosphere of La Plata station is illustrated in Figure 3 . As can be seen in the $|Z|$ versus frequency plots, the maximum and minimum impedance values were mostly in the range $10^{6}-10^{8} \Omega$, and $10^{3}-10^{5} \Omega$, respectively. Besides, a merely qualitative analysis of the angle phase $(\theta)$ versus Frequency plots allows to presume the presence of at least one time constant at low
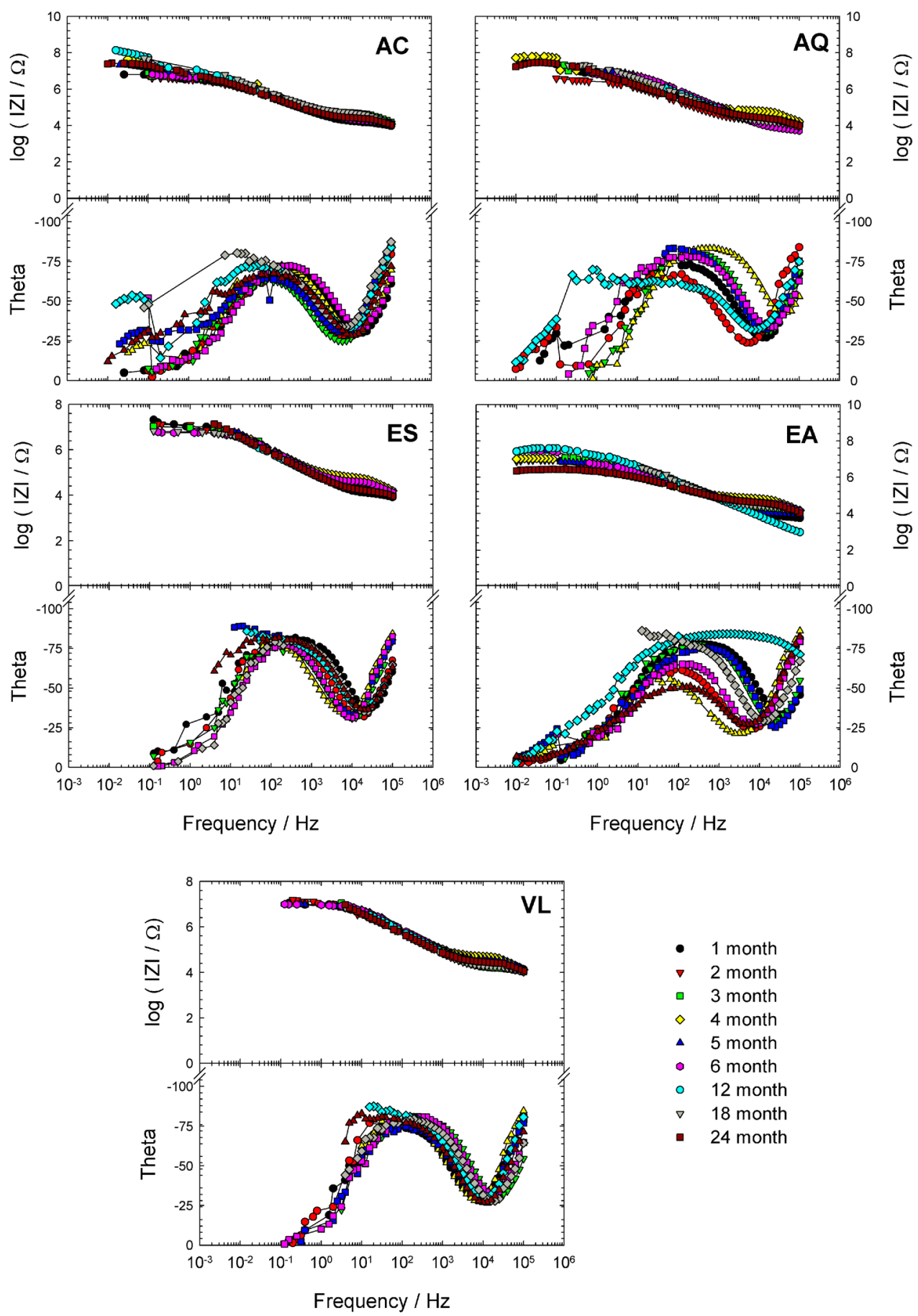

- 1 month

$\checkmark 2$ month

- 3 month

$\diamond 4$ month

- 5 month

- 6 month

- 12 month

$\nabla 18$ month

- 24 month

Frequency $/ \mathrm{Hz}$

Figure 3. Bode plots showing the time dependence of the $A C, A Q, E S, E A$ and $V L$ samples impedance during their exposure to the natural atmosphere of the La Plata station for 2 years. 
frequencies and another at high frequencies. With regard to the exposure test in either the natural atmosphere of Potosí or the accelerated weathering, only one impedance spectrum was obtained for each sample at the end of the test. Therefore, as no evolution can be compared, their Bode plots are not shown. Nevertheless, taking into account that some differences were found, their results will be discussed later.

Equivalent circuit models. The protective properties worsening of steel $/ 55 \% \mathrm{Al}-\mathrm{Zn} /$ painting systems take place due to processes having a complex nature. Consequently, to interpret and explain the time dependence of the acquired impedance data in electrochemical terms, it has been necessary to propose appropriate equivalent circuit models.

Impedance spectra provide useful information concerning the evolution of both the protective features of the organic coating and the kinetics of the underlying steel $/ 55 \% \mathrm{Al}-\mathrm{Zn}$ corrosion process as a function of the exposure time to artificial or real service conditions. Thus, the dynamic character of the painting system barrier properties, the anticorrosive action of specific pigments, the formation of corrosion products and changes in the disbonded area are accounted for in the time dependence of the coated steel/ electrolyte impedance spectra. In general, an explanation of why and how such changes took place can be given by associating them to the resistive and capacitive parameters derived from fitting impedance data with nonlinear least squares algorithms involving the transfer function of the equivalent circuit models shown in Figure $4 a-c$, which are generally reported in the literature. ${ }^{[[10 q, 22]]}$ They represent the parallel and/or series connection of some resistors and capacitors, simulating a heterogeneous arrangement of electrolitically conducting paths where: $R$ represents the electrolyte resistance between the reference (SCE) and working (coated steel) electrodes, $R_{1}$ (resistance to the ionic flux) describes paths (pores, low crosslinking) of lower resistance to the electrolyte diffusion shortcircuiting the paint film, and $C_{1}$ the dielectric capacitance representing the intact part of the same paint film. ${ }^{[23]}$ Once the permeating and corrosion inducing chemicals (water, oxygen and ionic species) reach electrochemically active areas of the substrate, mainly at the bottom of the paint film defects, the metallic corrosion becomes measurable so that its associated parameters, the electrochemical double layer capacitance, $C_{2}$, and the charge transfer resistance, $R_{2}$, can be estimated. Besides, when either the corrosion products are gathered within, and/or at the

a

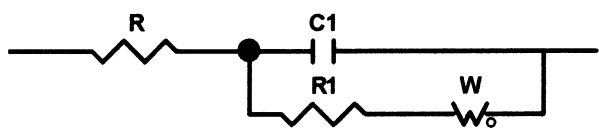

b
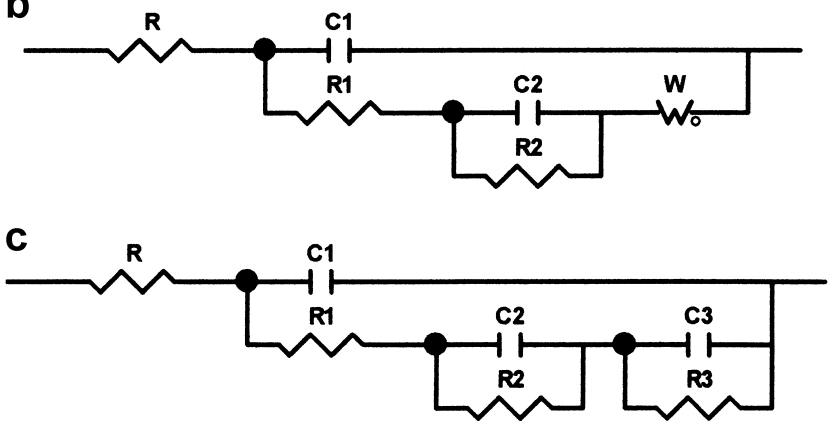

Figure 4. Equivalent circuit models used for fitting the tested samples. bottom of, the coating pores or the strength of the bonding forces at the paint/metal interface are affected (e.g. by wet adhesion) enabling lateral diffusion of the electrolyte, the appearance of another time constant $\left(R_{3} C_{3}\right)$ and/or a diffusion component (W) can be graphically and/or numerically separated. ${ }^{[24]}$ In this paper, and due to the high adhesion values measured for all the samples, the third time constant $\left(R_{3} C_{3}\right)$ was associated to the zinc corrosion products acting as a capacitor with low dielectric capacitance. Depending on which rate determining step (rds) is, the corrosion process will be under activate, diffusion or mix control.

On the other hand, distortions observed in these resistivecapacitive contributions indicate a deviation from the theoretical models in terms of a time constant distribution due to either lateral penetration of the electrolyte at the steel/paint interface (usually started at the base of intrinsic or artificial coating defects), underlying steel/55\% Al-Zn surface heterogeneity (topological, chemical composition and surface energy) and/or diffusional processes that could take place during the test. ${ }^{[25]}$ Since all these factors cause the impedance/frequency relationship to be nonlinear, they are taken into consideration by replacing one or more capacitive components $\left(C_{i}\right)$ of the equivalent circuit transfer function by the corresponding constant phase element $Q_{i}$ (CPE), whose impedance dispersion relation is given by ${ }^{[13,26]}$ :

$Z_{\mathrm{CPE}}=\frac{(j \omega)^{-n}}{Y_{0}}$

where $\omega$ is the angular frequency $(2 \pi f)$, and $f$ is the frequency, $Y_{0}$ is the admittance adjustable parameter, $n=$ CPE power.

Difficulties in providing an accurate physical description of the occurred processes are sometimes found. In such cases, a standard deviation value $\left(\chi^{2}<5 \times 10^{-4}\right)$ between experimental and fitted impedance data may be used as final criterion to define the 'most probable circuit'.[13]

According to the impedance spectra dispersion, the fitting processes were performed using either the dielectric capacitance $C_{i}$ or the phase constant element $Q_{i}$, however, the $C_{i}$ parameter was used in the following plots to facilitate the results visualisation and interpretation.

\section{Time Dependence of the Impedance Resistive and Capacitive} Components

\section{Exposure tests to natural or artificial atmospheres}

The values of the resistive and capacitive components of the impedance corresponding to the AC, AQ, ES, EA and VL samples exposed to the natural atmospheres of La Plata and Potosí stations for 2 years, and to the accelerated weathering test for $300 \mathrm{~h}$ were obtained and resistive ones are shown in Figure 5.

As can be seen, the agreement between the experimental results obtained for all the samples exposed to the accelerated weathering test for $300 \mathrm{~h}$ (Table 5), and then evaluated by EIS (Figure 5) is highly suitable. According to such results, all the samples offered an excellent protective performance since not only no blistering, cracking, checking, flaking or corrosion signal was visually detected (the grading was always 10 ), but also the values of the coating $\left(R_{1} \geq 10^{8} \Omega \mathrm{cm}^{2}, \quad C_{1} \approx 10^{-10} \mathrm{~F} \mathrm{~cm}^{-2}\right)$ and corrosion $\left(R_{2} \geq 10^{7} \Omega \mathrm{cm}^{2}, C_{2} \leq 10^{-9} \mathrm{~F} \mathrm{~cm}^{-2}\right)$ parameters allows one to infer that although there was an indistinguishable by the naked eye $55 \%$ $\mathrm{Al} / \mathrm{Zn}$ corrosion process, this took place at an extremely low rate. In line with this statement, the absence of the third time constant $\left(R_{3} C_{3}\right)$ demonstrated that the amount of gathered zinc corrosion 

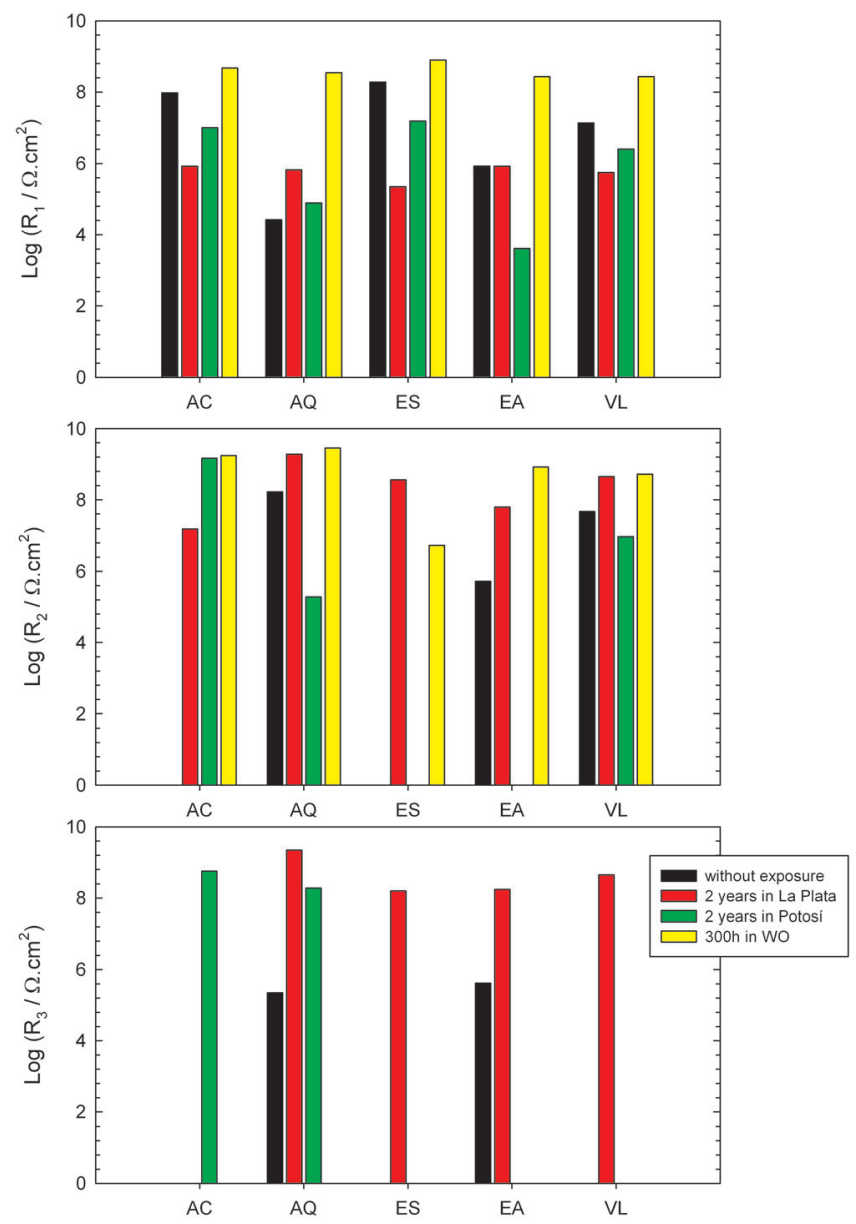

Figure 5. Values of $\log R_{1} ; \log R_{2}$ and $\log R_{3}$ of $A C, A Q, E S, E A$ and $V L$ samples without exposure and exposed to the natural atmospheres of $L a$ Plata and Potosí stations for 2 years, and to the accelerated weathering test for $300 \mathrm{~h}$.

products was below the threshold required to be detected by the very sensitive EIS technique.

On the other hand, when results coming from replicates of these samples subjected to the natural atmospheres of Potosí or La Plata stations were compared, some differences between them and those obtained from the accelerated weathering test were found. Figure 5 summarises the values of the electrical (painting system) and electrochemical (substrate corrosion) resistive parameters obtained from fitting the overall impedance of the samples exposed for 2 years in both stations. As can be seen, the samples exposed at the Potosí station showed high scattering of the ionic resistance $\left(R_{1}\right)$ values since these ranging from $1.02 \times 10^{7} \Omega \mathrm{cm}^{2}$ (ES samples) to $4.07 \times 10^{3} \Omega \mathrm{cm}^{2}$ (EA samples). As the topcoat paint formulation and thickness was the same for all the samples, such a difference was mainly attributed to the intrinsic permeability properties of each anticorrosive primer. In this respect, the solvent-base epoxy has largely demonstrated its excellent qualities. The coupled dielectric capacitance values $\left(C_{1} \approx 10^{-9}-10^{-11} \mathrm{~F} \mathrm{~cm}^{-2}\right)$ remained within those considered as characteristics of insulating organic coatings, therefore, they were interpreted by assuming that once saturated with water, neither the volume of this within the- nor the characteristics of the- painting system changed significantly. Besides, this means that the amount of water uptake in each case could be $<5 \%$ of the painting system volume ${ }^{[27]}$ over the test.
With regard to the electrochemical parameters values, larger differences were found since the rate determining step (rds) of the corrosion process in ES and EA samples was controlled by the cathodic reaction $\left(\mathrm{W} \approx 1 \times 10^{-9} \Omega^{-1} \mathrm{~cm}^{-2}\right)$, that is the oxygen diffusion towards the steel $/ 55 \% \mathrm{Al}-\mathrm{Zn}$ substrate, which completely masked the appearance of other resistive-capacitive parameters contributing to the whole impedance. On the other hand, even though the same type of rds was found for VL samples, the faradic contribution to the impedance could be evaluated so that the charge transfer resistance $\left(R_{2}=9.38 \times 10^{6} \Omega \mathrm{cm}^{2}\right)$ and electrochemical double layer capacitance $\left(C_{2}=3.65 \times 10^{-10} \mathrm{~F} \mathrm{~cm}^{-2}\right)$ values evidenced the existence of a $55 \% \mathrm{Al}-\mathrm{Zn}$ corrosion process much slower than the corresponding to the bare alloy in the same environment. ${ }^{[19]}$

For the AC and AQ samples, the $55 \% \mathrm{Al}-\mathrm{Zn}$ dissolution (anodic reaction) under active control was the rds. However, the AC samples presented better protective performance because despite the value of the respective coupled capacitances $\left(C_{1}\right.$ and $\left.C_{2}\right)$ was similar $\left(\cong 10^{-9} \mathrm{~F} \mathrm{~cm}^{-2}\right)$, their barrier $\left(R_{1} \cong 10^{7} \Omega \mathrm{cm}^{2}\right)$ and anticorrosive $\left(R_{2} \cong 10^{9} \Omega \mathrm{cm}^{2}\right)$ protection was great than the afforded by the AQ samples, whose respective resistances were $\cong 10^{5} \Omega \mathrm{cm}^{2}$. As well, the value of the resistive $\left(R_{3} \geq 10^{8} \Omega \mathrm{cm}^{2}\right)$ and capacitive $\left(C_{3} \leq 10^{-9} \mathrm{Fcm}^{-2}\right)$ parameters defining the time constant associated to the corrosion products (mainly $\mathrm{ZnO}$ and $\mathrm{Zn}_{4} \mathrm{CO}_{3}(\mathrm{OH})_{6} \cdot \mathrm{H}_{2} \mathrm{O}$ ) contribution to the overall samples impedance could be estimated in both cases. Such contribution was ascribed to their blocking action to accumulate within and/or the bottom the painting system defects.

With regard to the performance of the samples exposed in La Plata station, Figure 5, the evolution of the resistive $\left(R_{1}\right)$ and capacitive $\left(C_{1}\right)$ parameters contributing to the impedance of the different painting systems was quite similar and stable. So, in it can be seen that while the magnitude of $R_{1}$ remained within the range $10^{5}-10^{6} \Omega \mathrm{cm}^{2}$, the corresponding to $C_{1}$ did it between $10^{-10}$ and $10^{-11} \mathrm{~F} \mathrm{~cm}^{-2}$, that is, the organic coating behaved like a very small and stable reservoir of water. These values show that the estimated for $R_{1}$ were less than those recognised as an acceptable barrier resistance, that is, $R_{1}>10^{7} \Omega \mathrm{cm}^{2}$, ${ }^{[28]}$ however the small changes of $R_{1}$ and $C_{1}$ with the exposure time indicated that a structurally homogeneous and intact paint film was able to retain their relatively good barrier properties and, therefore, allowing for a limited substrate corrosion. Such assumption was supported by the evolution of $R_{2}, C_{2}, R_{3}$ and $C_{3}$ values since they mostly kept greater than $10^{7} \Omega \mathrm{cm}^{2}$ and $<10^{-8} \mathrm{~F} \mathrm{~cm}^{-2}$, respectively. These results, in good agreement with the visual assessment of corrosion and blistering carried out on the same samples (see Table 4), point out that even though very localised and often unlikely to be detected by the naked eye, there was electrochemically active areas at the metal/paint interface.

\section{CONCLUSIONS}

The experimental behaviour of the treated panels was evaluated through visual inspection (blistering and/or white corrosion as well as cracking, checking and/or flaking degrees) and EIS measurements (corrosion evolution). EIS spectra were interpreted and discussed in terms of the time dependence of the electrical (paint coating) and electrochemical (steel/55\% Al-Zn substrate) parameters associated with interfacial processes to describe the deterioration of the metal/paint system.

With regard to the other exposure conditions, it may be concluded that: (1) most of the painting systems performed satisfactorily during their exposure tests to either the accelerated 
weathering or the natural atmospheric environment (Potosí or La Plata stations) (2) the AC, ES and VL samples showed a small amount of white corrosion products in La Plata station, which was attributed to the painting system deterioration mainly due to intense sun radiation. The correlation of results from the standardised and electrochemical tests allowed for the explanation of some problems observed in practice and opened the door to extend the useful life by improving the paint formulation and/or the painting system design.

All the laboratory and field tests involved in this work were useful to understand the behaviour of the studied painting systems subjected to either natural or simulate but highly aggressive environments. The good correlation between standardised (blistering, white corrosion, natural or accelerated weathering) and electrochemical (impedance spectra, corrosion potential) tests allowed explaining some troubles observed in practice and, on this base, contribute to solve them changing some components and/or concentrations of the paint formulation to maintain its useful life as long as it is possible. Besides, the observed dissimilarity by comparing the anticorrosive protective properties afforded by a given painting system exposed to different media support the idea that extrapolate protective performances from an exposure condition to other is absolutely risky.

\section{ACKNOWLEDGEMENTS}

The authors thank to the Comisión de Investigaciones Científicas de la Provincia de Buenos Aires (CICPBA), the Consejo Nacional de Investigaciones Científicas y Técnicas (CONICET) and the Universidad Nacional de La Plata of Argentina, also to the Consejo Nacional de Investigaciones Científicas y Técnicas (CONACYT) of México by the financial support to carry out the present research paper. They also thank to the Engr. A. Aznar by the formulation of the acrylic and epoxy waterborne paints.

\section{REFERENCES}

[1] M. Stratmant, K. Bohnenkamp, W. J. Engell, Corros. Sci. 1983, 23, 969.

[2] D. de la Fuente, J. G. Castaño, M. Morcillo, Corros. Sci. 2007, 49, 1420.

[3] (a) C. E. Bird, F. J. Strauss, Mater. Performance 1976, 15, 27; (b) F. E. Goodwin, in Zinc-Based Steel Coatings Systems: Metallurgy and Performance, G. Krauss, Ed., The Minerals, Metals \& Materials Society, Warrendale, PA, USA 1990, p. 183; (c) M. Pourbaix, Une méthode éléctrochimique rapide de predetermination de la corrosion atmospherique, Rapports Techniques CEBELCOR, Vol. 109, R. T. No. 160, 1969.

[4] Y. Suzuky, Y. Hisamatsu, N. Masuko, J. Electrochem. Soc. 1980, 127, 2210.

[5] J. C. Zoccola, H. E. Townsend, A. R. Borzillo, J. B. Horton, STP 646, ASTM 1978, 165.

[6] (a) H. E. Townsend, L. Allegra, R. J. Dutton, S. A. Kriner, Mater. Performance 1986, 25, 36; (b) H. E. Townsend, A. R. Borzillo, Mater. Performance 1987, 26, 37.

[7] F. Porter, Zinc Handbook Properties, Processing and Use in Design Duplex Coatings, M. Dekker Inc., New York 1991 p. 363.

[8] J. F. H. Van Eijnsbergen, Duplex Systems-Hot Dip Galvanising Plus Painting, Vol. 7, Elsevier Science B.V., New York, NY 1994 p. 75.
[9] (a) K. L. Mittal, in Adhesion Measurements of Film and Coatings, K. L. Mittal, Ed., VSP, Utrecht, The Netherlands 1995 p. 299; (b) Structure Steel Painting Coating, Systems and Specifications, Vol. 2, 7th edition, Steel Structures Painting Council, Pittsburgh 1995 p. 9.

[10] (a) C. Porter, Painted Steel. Naval Bureau of Standards, Report \#BMS-102, National Bureau of Standards, Washington, DC 1994; (b) J. Bigos, H. H. Greene, G. R. Hoover, Five Years Test Results: AISI Research Project on Paintability of Galvanised Steel, American Iron and Steel Institute, New York, NY 1967 p. 316; (c) B. P. Jourdan, C. I. Elsner, A. R. Di Sarli, Anales de las Jornadas SAM/CONAMET 2001, Vol. 2, Posadas-Misiones, Argentina 2001 p. 723; (d) E. A. Sacco, J. D. Culcasi, C. I. Elsner, A. R. Di Sarli, Latin Am. Appl. Res. 2002, 32, 307; (e) E. A. Sacco, J. J. Caprari, C. I. Elsner, A. R. Di Sarli, Actas del Congreso SAM/CONAMET/SIMPOSIO MATERIA 2003, San Carlos de Bariloche, Argentina. Version CD ISBN: 987-20975-0-X; (f) I. Sekine, M. Yuasa, N. Hirose, T. Tanaki, Prog. Org. Coat. 2002, 45, 1; (g) G. Rocchini, Corr. Prev. Control 2001, 48, 125; (h) S. Maeda, Prog. Org. Coat. 1996, 28, 227; (i) R. L. Howard, S. B. Lyon, J. D. Scantlebury, Prog. Org. Coat. 1999, 37, 91; (j) R. L. Howard, S. B. Lyon, J. D. Scantlebury, Prog. Org. Coat. 1999, 37, 99; (k) S. Feliú, V. Barranco, S. Feliú, Prog. Org. Coat. 2004, 50, 199; (1) R. A. Di Sarli, R. A. Armas, Corr. Prev. Control 1989, 36, 127; (m) P. R. Seré, J. D. Culcasi, C. I. Elsner, A. R. Di Sarli, Proc. of SCANNING 98, Baltimore-Maryland, USA, Vol. 20, 1998, p. 274; (n) M. B. Rosales, A. R. Di Sarli, PATINA Network National Coordinators. F. Fragata, F. Corvo, M. S. de Villalaz, S. Flores, E. Almeida, J. Simancas, S. Rivero, O. T. de Rincón, Revista de Metalurgia Vol. Extr. 2003, 201; (o) B. M. Rosales, A. R. Di Sarli, O. de Rincón, A. Rincón, C. I. Elsner, B. Marchisio, S. Flores, S. Rivero, Prog. Org. Coat. 2004, 50, 105; (p) B. Amo, L. del Véleva, C. I. Elsner, A. R. Di Sarli, Prog. Org. Coat. 2004, 50, 179.

[11] (a) A. Gerhard, A. Bittner, J. Coat. Technol. 1986, 58, 59; (b) A. Bittner, J. Coat. Technol. 1989, 61, 14.

[12] G. Adrian, A. Gerhard, A. Bittner, M. Gawol, Farbe u. Lack $1981,7,833$.

[13] B. A. Boukamp, Report CT88/265/128, CT89/214/128. University of Twente, The Netherlands 1989.

[14] E. V. Schmid, Exterior Durability of Organic Coatings. FMJ International Publications Ltd., Redhill 1988, p. 2.

[15] (a) W. Schwenk, "Corrosion Control by Organic Coatings" in Adhesion Loss of Organic Coatings-Causes and Consequences for Corrosion Protection, H. Leidheiser, Jr., Ed., NACE, Houston, TX 1981, p. 103; (b) H. Leidheiser, Jr., W. Funke, J. Oil Colour Chem. Assoc. 1987, 70, 121; (c) L. De Rosa, T. Monetta, D. B. Milton, F. Bellucci, J. Electrochem. Soc. 1998, $145,3830$.

[16] C. I. Elsner, A. R. Di Sarli, J. I. Amalvy, A. C. Aznar, Anais do $10^{\circ}$ Congresso Internacional de Tintas ABRAFATI 2007. October 24-26, 2007, San Pablo, Brazil. Edited in CD, p. 1.

[17] J. Wolstenholme, Corros. Sci. 1973, 13, 521.

[18] (a) R. A. Armas, C. Gervasi, A. R. Di Sarli, S. G. Real, J. R. Vilche, Corrosion 1992, 48, 379-383; (b) J. E. O. Mayne, Off. Dig. 1952, 24, 127; (c) L. Meszáros, S. A. Lindquist, Proc. Conference EUROCORR'82-115th Event of the European Federation for Corrosion, Budapest, Hungary, 18-22 October, Section 11, 1982, p. 147; (d) M. Morcillo, R. Barajas, S. Feliú, J. M. Bastidas, J. Mater. Sci. 1990, 25, 2441. 
[19] C. I. Elsner, P. R. Seré, A. R. Di Sarli, Inter. J. Corr. (Special Issue on Atmospheric Corrosion) 2012, 2012, Article ID 419640, p. 16. doi: $10.1155 / 2012 / 419640$

[20] M. W. Kendig, H. Leidheiser, Jr., J. Electrochem. Soc. 1976, 123, 982.

[21] (a) A. Guenbour, J. Faunchen, A. Ben Bachir, Corrosion 1988, 44, 214; (b) J. R. Ambrose, Corrosion 1978, 34, 27.

[22] (a) O. Ferraz, E. Cavalcanti, A. R. Di Sarli, Corros. Sci. 1995, 37, 1267; (b) P. R. Seré, M. Zapponi, C. I. Elsner, A. R. Di Sarli, Corros. Sci. 1998, 40, 1711; (c) D. M. Santágata, P. R. Seré, C. I. Elsner, A. R. Di Sarli, Prog. Org. Coat. 1998, 33, 44; (d) P. R. Seré, A. R. Armas, C. I. Elsner, A. R. Di Sarli, Corros. Sci. 1996, 38, 853; (e) G. Grundmeier, W. Schmidt, M. Stratmann, Electrochim. Acta 2000, 45, 2515; (f) L. Jianguo, G. Gaoping, Y. Chuanwei, Electrochim. Acta 2005, 50, 3320; (g) A. Conde, J. J. Damborenea, Corros. Sci. 2002, 44, 1555; (h) M. Hernández, J. Genescá, J. Uruchurtu, A. Barba, Corros. Sci. 2009, 51, 499; (i) C. Pérez, A. Collazo, M. Izquierdo, P. Merino, X. R. Nóvoa, Corros. Sci. 2002, 44, 481; (j) B. Chico, J. C. Galván, D. de la Fuente, M. Morcillo, Prog. Org. Coat. 2007, 60, 45; (k) F. Deflorian, S. Rossi, L. Fedrizzi, P. L. Bonora, Prog. Org. Coat. 2005, 52, 271; (l) X. Liu, J. Xiong, Y. Lv, Y. Zuo, Prog. Org. Coat. 2009, 64, 497; (m) L. Liu, Y. Cui, Y. Li, T. Zhang, F. Wang, Electrochim. Acta 2012, 62, 42; (n) P. Wang, D. Zhang, R. Qiu, J. Wu, Y. Wan, Corros. Sci. 2013, 69, 23.

[23] H. Leidheiser, Jr., M. W. Kendig, Corrosion 1976, 32, 69.

[24] G. G. Nascimento, O. R. Mattos, J. L. Santos, I. C. P. Margarit, J. Appl. Electrochem. 1999, 29, 383.

[25] (a) T. Szauer, A. Brandt, J. Oil Colour Chem. Assoc. 1984, 67, 13; (b) D. J. Frydrych, G. C. Farrington, H. E. Townsend, in Corrosion Protection by Organic Coatings, M. W. Kendig, H. Leidheiser, Jr. Eds., vol. 87-872. The Electrochem. Soc., Pennington, NJ 1987, p. 240.

[26] E. P. M. Van Westing, G. M. Ferrari, F. M. Geenen, J. H. W. van de Wit, Prog. Org. Coat. 1993, 23, 89.

[27] D. M. Brasher, A. A. Kingsbury, J. Appl. Chem. 1954, 4, 62.

[28] C. I. Elsner, A. R. Di Sarli, J. Braz. Chem. Soc. 1994, 5, 15.

Manuscript received December 26, 2012; revised manuscript received March 12, 2013; accepted for publication March 20, 2013. 